\title{
Características vegetativas do coentro submetido a doses do polímero hidroabsorvente e lâminas de irrigação ${ }^{1}$
}

\author{
João A. C. de Albuquerque Filho ${ }^{2}$, Vera L. A. de Lima ${ }^{3}$, Dimas Menezes ${ }^{4}$, \\ Carlos A. V. Azevedo ${ }^{3}$, José Dantas Neto ${ }^{3} \&$ José G. da Silva Júnior ${ }^{5}$
}

\begin{abstract}
RESUMO
Este trabalho teve o objetivo de avaliar o efeito de cinco doses do polímero hidroabsorvente hidratassolo ${ }^{\bullet}, 0,4,8,12 \mathrm{e}$ $16 \mathrm{dg} \mathrm{kg}^{-1}$ de solo seco, e duas lâminas de irrigação, 60 e 120\% da evapotranspiração de referência, nas características vegetativas do coentro. Adotou-se um delineamento experimental inteiramente casualizado em parcela sub-dividida no tempo, com quatro repetições. Nas duas épocas de plantio do coentro a eficiência do uso da água, o rendimento de matéria verde e seca e o número de plantas aumentaram linearmente com a elevação das doses do polímero quando se fixou a menor lâmina, exceto na predição da altura de plantas na primeira época de plantio conforme modelo quadrático. Com a aplicação da maior lâmina as estimativas das características avaliadas com interação significativa foram maximizadas com doses ideais na faixa de 6 a $11 \mathrm{dg} \mathrm{kg}^{-1}$, como também o emprego da dose máxima de $16 \mathrm{dg} \mathrm{kg}^{-1}$ proporcionou uma queda em relação à testemunha.
\end{abstract}

Palavras-chave: condicionador de solo, lisímetro de drenagem, manejo de irrigação

\section{Vegetative characteristics of coriander submited to doses of the hydrogel polymer and water depths}

\begin{abstract}
This study had the objective of evaluating the effect of five doses of the hidratassolo ${ }^{\circledR}$ hydrogel polymer $0,4,8,12$ and $16 \mathrm{dg} \mathrm{kg}^{-1}$ of dry soil, and two irrigation water depths, 60 and $120 \%$ of the reference evapotranspiration, on the vegetative characteristics of coriander. A completely randomized experimental design was adopted in split-plots, with four replications. At two stages of coriander growth the water use efficiency, the yield of green and dry matter, and the number of plants increased linearly with the elevation of dose of the polymer, when the smallest water depth was applied, except in the prediction of the height of plants at the first stage of planting according to quadratic model. With application of higher water depth $(120 \%)$, the estimates of the appraised characteristics with significant interaction were maximized with ideal doses in the range of 6 to $11 \mathrm{dg} \mathrm{kg}^{-1}$, and also the employment of the maximum dose of $16 \mathrm{dg} \mathrm{kg}^{-1}$ provided a fall in relation to the control.
\end{abstract}

Key words: soil conditioner, drainage lysimeter, irrigation management

\footnotetext{
1 Parte da Tese de Doutorado do primeiro autor apresentada à UFCG.

2 DTR/UFRPE, CEP 52171-900, Recife, PE. Fone: (81) 3320-6275. E-mail: jaudifax@dtr.ufrpe.br

3 UAEA/UFCG, CEP 58429-170, Campina Grande, PB. E-mail: antuneslima@gmail.com, cazevedo@deag.ufcg.edu.br, zedantas@deag.ufcg.edu.br.

${ }^{4}$ DEPA/UFRPE, CEP 52171-900, Recife, PE. Fone: (81) 3320-6245. E-mail: dimas0@dtr.ufrpe.br; dimas@depa.ufpe.br

Mestre DTR/UFRPE, CEP 52171-900, Recife, PE. Fone: (81) 3320-6275. E-mail: gracilianojrster@gmail.com
} 


\section{INTRODUÇÃO}

A necessidade de aumentar a produção de alimentos aliada à globalização do comércio e à competitividade dos produtos agrícolas tem estimulado cooperativas e produtores a buscarem técnicas alternativas para a melhoria da produtividade e redução de custos. Deste modo, os polímeros hidrorretentores passaram a ser pesquisado como forma de minimizar os problemas associados à baixa produtividade, geralmente provocada pela disponibilidade irregular ou deficitária de água e má estruturação do solo (Fonteno \& Bilderback, 1993).

Inicialmente utilizados como alternativa de produção para as regiões de clima árido, a aplicação de polímeros tornouse conhecida nas diferentes partes do planeta diversificando-se, sobremaneira, em hortaliças e culturas anuais, razão pela qual a maior parte das pesquisas realizadas mostrou-se favorável ao seu emprego nos solos agrícolas apresentando, como principal fator de convergência, a melhor utilização da água (Baasiri et al., 1986).

Com o objetivo de reunir o maior número de informações da literatura a respeito do uso de hidrogéis na agricultura, Azevedo et al. (2002) concluíram que grande parte dos trabalhos evidenciou as propriedades dos hidrogéis como condicionadores de solo proporcionando-lhe melhoria nas propriedades físicas e hidráulicas.

No Brasil, polímeros sintéticos hidroabsorventes, como o Hidratassolo e o Terracottem, têm sido utilizados na produção de mudas e no substrato de transplantio para essências florestais, hortaliças, flores, gramados e jardins, visando aumentar a disponibilidade de água no solo para as plantas (Baasiri et al., 1986; Wallace, 1987). A adição dessa substância ao solo contribui para a germinação de sementes, desenvolvimento do sistema radicular, crescimento e desenvolvimento das plantas, redução das perdas de água de irrigação por percolação, melhoria na aeração e drenagem do solo além de redução das perdas de nutrientes por lixiviação (Henderson \& Hensley, 1986).

Danneels \& van Cotthem (1994) observaram ganhos significativos na biomassa e no aumento na eficiência do uso de água, quando plantas como pimentão, feijão e milho, foram cultivadas em uma mistura contendo areia e doses crescentes de condicionador de solo. Bernardi et al. (2005) avaliam o efeito de um polímero hidrofílico em diferentes frequências de irrigação sobre a produção do meloeiro, em casa-de-vegetação e verificam que a dose ideal do polímero foi na faixa de 5 a $6 \mathrm{~g} \mathrm{~kg}^{-1}$ de solo e a utilização desta dose possibilitou adotar-se um intervalo de um dia entre as irrigações.

A influência desses polímeros sobre a dinâmica da água no solo e seu efeito positivo sobre a disponibilidade hídrica para as plantas cultivadas têm sido amplamente documentados (Taylor \& Halfacre, 1986; Johnson, 1984; Orzolek, 1993). A literatura oferece, entretanto, crescentes evidências de que o emprego dos polímeros no solo é útil em baixas condições de aridez, embora alguns deles propiciem benefícios na produção de espécies hortícolas cultivadas em condições de estresse hídrico moderadas (Pill \& Jacono, 1984;
Taylor \& Halfacre, 1986), e se tem demonstrado que melhoram a eficiência no uso da água em diferentes sistemas de cultivo (Tittonel et al., 2002).

Segundo Woodhouse \& Johnson (1991), a eficiência do uso da água não é apenas uma medida de quanta água é requerida para produzir uma unidade de peso seco, mas é de particular significação na avaliação de desempenho de polímero em um sistema de crescimento solo-planta, haja vista que integra evapotranspiração pela planta e evaporação da mistura de areia-polímero. Na prática, eficiência do uso da água é uma medida conveniente para avaliar o desempenho técnico de um polímero porque um aumento na eficiência do uso da água é frequentemente uma indicação de que as perdas de água do conjunto solo-polímero estão sendo reduzidas.

Oliveira et al. (2004) verificam que, na medida em que a concentração do polímero nos solos aumentou, ocorreu maior retenção de água e redução nas perdas por percolação e da quantidade de água necessária para várias culturas (Baasiri et al., 1986). Bernardi et al. (2005) afirmam que esses produtos são capazes de reter grandes quantidades de água, sendo oportuno testá-los para diferentes culturas e condições edafoclimáticas, para se definir as quantidades e formas de aplicação mais adequadas.

De acordo com Pereira et al. (2005) tem-se feito pouca pesquisa com o cultivo do coentro, incluindo a tecnologia adequada para sua produção, a que se soma a escassez de informações a respeito de sua produção e comercialização; neste contexto se objetivou, através deste trabalho, avaliar o efeito de lâminas de irrigação e doses crescentes do polímero hidroabsorvente Hidratassolo ${ }^{\circledR}$ na eficiência do uso da água e nas características vegetativas do coentro cultivado em solo arenoso, em duas épocas de plantio.

\section{MATERIAL E MÉTODOS}

\section{Caracterização do local}

O estudo foi conduzido na área experimental, no Departamento de Tecnologia Rural localizada no Campus da Universidade Federal Rural de Pernambuco, Recife, PE, cujas coordenadas geográficas no sistema SAD 69 (South American Datum), são $8^{\circ} 01^{\prime} 05^{\prime \prime}$ de latitude sul e $34^{\circ} 56^{\prime} 48^{\prime \prime}$ de longitude oeste e altitude de 6,486 m. O clima, de acordo com a classificação de Koppen, é As, Megatérmico tropical (tropical úmido), com temperatura média do mês mais frio superior a $18{ }^{\circ} \mathrm{C}$ com precipitações de outono e inverno.

Utilizou-se, na área experimental, de uma bateria de 40 lisímetros de drenagem distribuídos em oito fileiras. Cada lisímetro era constituído de uma caixa de Cimento Reforçado com Fio Sintético - CRFS (linha Brasiflex - Brasilit), troncônicas, com capacidade de 1000 L, isto é, diâmetro externo na borda superior $1380 \mathrm{~mm}$ e altura externa de $745 \mathrm{~mm}$.

Em cada linha de cinco lisímetros havia uma cobertura removível, no total de oito, objetivando-se proteger o experimento da interferência de chuvas, Figura 1A. Os lisímetros possuem um sistema de drenagem de fundo interligado, individualmente, a uma estação de coleta de efluente, Figura 1B. 
A.

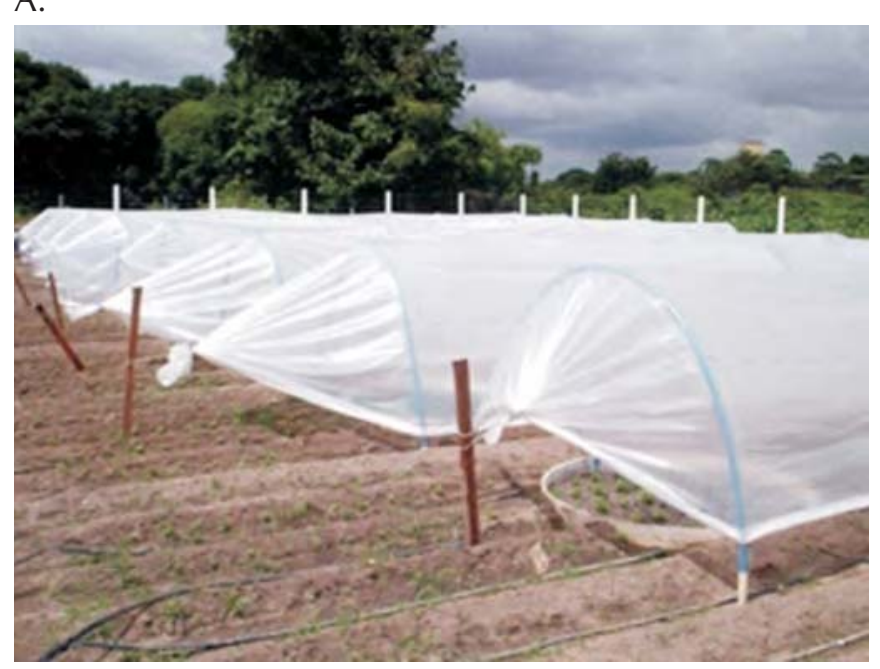

B.

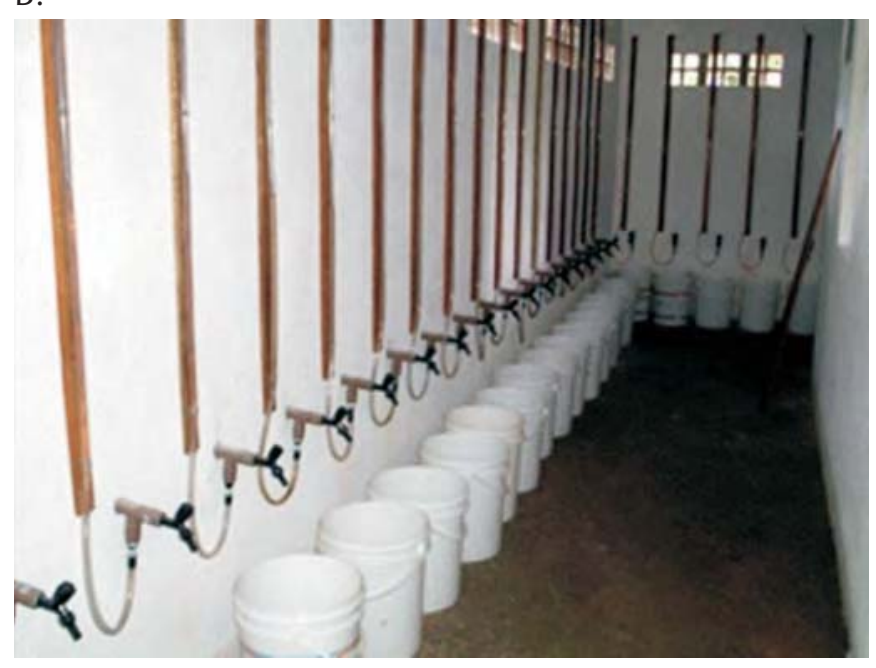

Figura 1. Cobertura removível (A) e estação de coleta de drenagem (B)

Conforme tratamento testemunha, em cada lisímetro foram colocados cerca de $900 \mathrm{~kg}$ do material de solo homogeneizado e passado em peneira com malha de $4,0 \mathrm{~mm}$, de forma a proporcionar um meio uniforme e homogêneo no interior dos lisímetros, até a altura de $54,5 \mathrm{~cm}$ medida em relação ao ponto central da circunferência, situado na superfície côncava, no fundo da caixa. Considerando a expansão volumétrica do polímero optou-se em quantificar a massa de hidratassolo a ser incorporada ao lisímetro, com base em peso de $300 \mathrm{~kg}$ de solo seco e equivalente à camada de $16 \mathrm{~cm}$ estabelecida para o desenvolvimento da zona radicular da cultura.

O processo de preenchimento foi padronizado com aplicações sequenciadas de $100 \mathrm{~kg}$ de solo seco, de forma a se obter densidades semelhantes no perfil de todos os lisímetros. Nas caixas que receberam as doses de hidratassolo ${ }^{\circledR}$ iniciou-se o preenchimento com material de solo até atingir a quantidade de $500 \mathrm{~kg}$ correspondente à altura da camada de 33,50 cm; em seguida, as doses foram lançadas manualmente e distribuídas de maneira uniforme sobre as superfícies de oito camadas de $2 \mathrm{~cm}$ do material de solo, até completar o total de $300 \mathrm{~kg}$. Para finalizar o processo aplicaram-se $100 \mathrm{~kg}$ do material de solo seco, relativos à última camada de $5 \mathrm{~cm}$, necessária ao recobrimento da mistura; esta última camada visou afastar a possibilidade de afloramento do produto na superfície do solo e sua consequente biodegradação; desta forma, a superfície final do solo ficou com $10 \mathrm{~cm}$ de folga até a borda superior da caixa.

O material de solo utilizado no preenchimento das parcelas foi caracterizado com $91 \%$ de areia (Neossolo Quartzarênico), coletado a $50 \mathrm{~cm}$ de profundidade no lote $70 \mathrm{da}$ Destilaria Tabu, a qual se situa no Estado da Paraíba, distante $80 \mathrm{~km}$ de Recife. O solo transportado, totalizando $57 \mathrm{t}$, após ser descarregado no local do experimento foi espalhado e homogeneizado em peneira de $4,0 \mathrm{~mm}$.

\section{Tratamentos e análises estatísticas}

Os tratamentos foram dispostos em esquema de parcela subdividida no tempo, tendo nas parcelas o esquema fatorial 5 x 2, cinco níveis de hidratassolo, 0, 4, 8, 12 e $16 \mathrm{dg} \mathrm{kg}^{-1}$ de solo seco, e as lâminas de irrigação em dois níveis (calculadas com base na evapotranspiração estimada a partir da evaporação no tanque Classe A), correspondentes a 60 e $120 \%$ da ETo. Nas subparcelas se colocou as épocas de colheita $\mathrm{T}_{1}$ e $\mathrm{T}_{2}$, no delineamento inteiramente casualizado, com quatro repetições.

Os dados foram analisados no sistema computacional SAEG (2005) e interpretados por meio das significâncias das análises de variância e regressão, adotando-se o nível de probabilidade de $5 \%$ pelo teste F. Para estabelecer o modelo representativo do fenômeno estudado utilizou-se o teste " $t$ " de Student para testar os coeficientes de regressão e se adotou o nível de probabilidade de $10 \%$ e os coeficientes de determinação $\mathrm{R}^{2}$.

\section{Primeira época de plantio do cultivo do coentro}

O coentro (Coriandrum sativum L.), cultivar Tabocas, foi plantado a partir de sementes produzidas pela Hortivale. A semeadura foi realizada diretamente nos lisímetros, no dia 06 de fevereiro de 2006. Antes do plantio as sementes foram fracionadas com um rolo de madeira visando aumentar a velocidade de germinação sem, contudo, alterar a germinação total, de acordo com Pereira et al. (2005). Conforme Filgueira (1982), a utilização de "sementes partidas" (aquênios) tem sido citada na literatura visando ao aumento da porcentagem de germinação; desta forma, utilizaram-se 8 "sementes partidas" por cova, no total de 40 covas por lisímetro; as covas foram distribuídas, formando quatro fileiras centrais com oito touceiras cada uma e duas fileiras mais externas com quatro covas, no espaçamento de $15 \mathrm{~cm}$ entre plantas na linha e $23 \mathrm{~cm}$ entre linha. Nas áreas de bordadura realizou-se a semeadura, nos dias $11 \mathrm{e}$ 12 de fevereiro; as touceiras, espaçadas $15 \times 30 \mathrm{~cm}$ entre linha, no sistema de sulcos (leiras), tinha declive de $3 \%$ no sentido transversal da área.

A fim de minimizar o efeito-oásis se semearam, no dia 09 de fevereiro, sementes da mesma cultivar, na área entre os lisímetros, também na faixa de 1,20 m contornando a área onde estão instalados os lisímetros, perfazendo uma área total 
de bordadura de aproximadamente $320,80 \mathrm{~m}^{2}$; o desbaste ocorreu quando as plantas atingiram uns $10 \mathrm{~cm}$ de altura, cortando-se as mais fracas e se deixando em cada unidade em torno de 360 plantas, ou 9 plantas por cova, com o objetivo de manter o estande de plantas mais uniforme.

Fez-se a adubação de plantio aplicando-se, em cada lisímetro de 1,41 m², $195 \mathrm{~g}$ da fórmula (4-14-8) granulado e $1,50 \mathrm{~kg}$ de humus, distribuídos uniformemente e misturados aos $5 \mathrm{~cm}$ de solo deixando-se, em seguida a superfície plana. Entre os $21^{\circ}$ e $45^{\circ}$ dias após o plantio, realizou-se uma adubação de cobertura de 8 em 8 dias, com uréia; utilizaram-se $10 \mathrm{~g}$ por lisímetro diluídos em $2 \mathrm{~L}$ de água e aplicados com regador de mão antes da irrigação. Realizaram-se, também, três pulverizações com fertilizante verde foliar da Vitaplan com $15 \%$ de $\mathrm{N}$, diluindo-se $5 \mathrm{~mL}$ em $20 \mathrm{~L}$ aplicados em todos os lisímetros.

Do plantio até o dia 24 de fevereiro, período considerado do estabelecimento do estande $\left(18^{\circ} \mathrm{dia}\right)$, os lisímetros foram irrigados duas vezes por dia, isto é, pela manhã, às $8 \mathrm{~h}$ e ao final da tarde, às $16 \mathrm{~h}$ e $30 \mathrm{~min}$. Aplicou-se, em cada rega, uma lâmina de $5,00 \mathrm{~mm}$ correspondente a $7 \mathrm{~L}$ repondo-se aproximadamente $100 \%$ da evaporação diária do tanque Classe A e se iniciou, no dia 25 de fevereiro a primeira saturação do solo nos lisímetros, além da contagem do tempo de controle dos balanços hídricos. Aplicaram-se, em média, 4 regadores de $14 \mathrm{~L}$ por parcela equivalentes à lâmina de $40 \mathrm{~mm}$; em seguida, se anotavam, antes de se iniciar o processo de saturação as leituras dos piezômetros no início da manhã, na sala de coleta e medição do efluente. Observando-se a ascensão e o equilíbrio do nível dos meniscos, nos piezômetros, iniciava-se o processo de drenagem do material lixiviado abrindo-se as torneiras até o dia seguinte, quando cessava a drenagem visto que, desta forma, se considerava a umidade do solo próximo à capacidade de campo.

Efetuaram-se os balanços hídricos nos dias 07, 15 e 23 de Março; utilizou-se o mesmo procedimento na saturação do solo na medição do volume total de água aplicado no período e o volume total drenado no dia do fechamento do balanço; assim, os volumes parciais de entrada e de saída foram contabilizados em um balde de $20 \mathrm{~L}$ tarado de litro em litro, e as frações de litro medidas em um Becker graduado de até $1 \mathrm{~L}$.

\section{Segunda época de plantio do cultivo do coentro}

Nesta fase a condução do experimento seguiu a metodologia descrita na primeira época, ou seja, plantio direto, realizado em 29 de março; adubação; controle nutricional e igual manejo da irrigação; entretanto, até o desbaste da cultura e o estabelecimento do estande, 27 dias após semeadura, decidiu-se realizar três balanços hídricos com lâminas constantes nas seguintes datas: 9, 17 e 25 de abril. Aplicaram-se diariamente, $10,64 \mathrm{~mm}(15 \mathrm{~L})$ fracionados em três regas; em seguida, nos dias 3, 11 e 19 de maio se realizaram os três últimos balanços hídricos, com aplicação do fator lâminas de irrigação estudadas: $\mathrm{L}_{1}$ e $\mathrm{L}_{2}$. Da mesma forma também se realizou o controle de ervas daninhas nos lisímetros e nas áreas externas de bordadura, durante o ciclo da cultura.

\section{Determinação da evapotranspiração máxima da cultura ETc}

Realizou-se a determinação da evapotranspiração máxima da cultura por meio do balanço de água nos lisímetros. Considerou-se o fluxo de água apenas no sentido vertical e a variação no armazenamento de água da planta desprezível; assim, o balanço hídrico foi estimado conforme Aboukhaled et al. (1982):

$$
\mathrm{P}+\mathrm{I}-\mathrm{ET}-\mathrm{D}=\Delta \mathrm{U}
$$

em que:

$$
\begin{aligned}
& \text { P - precipitação pluvial, mm } \\
& \text { I - lâmina de água aplicada, mm } \\
& \text { ET - evapotranspiração, mm } \\
& \text { D - percolação, mm } \\
& \Delta \mathrm{U} \text { - variação no conteúdo de água no solo, mm }
\end{aligned}
$$

De vez que o balanço de água é determinado entre duas ocorrências consecutivas de drenagem, a variação da umidade no solo se tornará desprezível haja vista que, depois de cessada a drenagem, o conteúdo de água no solo contido no lisímetro volta à capacidade de campo, sendo que a ET considerada será a média dos valores ocorridos nos intervalos de tempo entre as drenagens (Aboukhaled et al., 1982); desta forma, a Eq. 1 se reduz a:

$$
\mathrm{ET}=\mathrm{P}+\mathrm{I}-\mathrm{D}
$$

Como não houve penetração de água de chuva nos lisímetros durante a condução do experimento a Eq. 2 reduz-se a:

$$
\mathrm{ET}=\mathrm{I}-\mathrm{D}
$$

\section{Determinação da evapotranspiração de referência ETo}

As leituras de evaporação foram feitas diariamente, às $9 \mathrm{~h}$, medindo-se o nível de água no interior do poço tranquilizador com micrômetro de gancho, que permite leituras com precisão de $0,01 \mathrm{~mm}$. Calcularam-se os dados de evaporação diária pela diferença entre duas leituras consecutivas descontando-se as possíveis precipitações (Sediyama, 1987).

Obteve-se a evapotranspiração de referência ETo através da Eq. 4:

$$
\mathrm{ETo}=\mathrm{K}_{\mathrm{p}} \mathrm{x} \text { ECA }
$$

em que:

$$
\begin{aligned}
\text { ETo - evapotranspiração de referência, } \mathrm{mm} \mathrm{d}^{-1} \\
\mathrm{~K}_{\mathrm{p}} \text { - coeficiente do tanque, adimensional } \\
\text { ECA - evaporação medida no tanque Classe A, } \\
\quad \text { mm d }^{-1}
\end{aligned}
$$

\section{Determinação das variáveis resposta do experimento}

As colheitas foram realizadas manualmente, em 24 de fevereiro e 20 de maio, $46^{\circ}$ e $52^{\circ}$ dias após a semeadura, respectivamente, ocasião em que se fez a avaliação das plantas da parcela útil que correspondeu às 16 touceiras centrais: altura de plantas APU, número de plantas por parcela NPP, rendimento de massa verde RMV e rendimento de massa seca 
RMS da parte aérea da planta.

Avaliou-se a altura de plantas a partir do nível do solo até a extremidade das folhas mais altas, expressa em centímetros; após esta avaliação teve início a colheita das plantas, que foram colocadas em sacos de papel identificados e, em seguida, conduzidos para a bancada na qual, individualmente, se cortaram as raízes de cada touceira para contabilizar o número de plantas por parcela. A fim de caracterizar o crescimento vegetativo e a produtividade da cultura, avaliou-se o rendimento de massa verde da parte aérea das plantas obtido utilizando-se a massa fresca das plantas, expresso em $t^{h a^{-1}}$ e se determinou, como componente de produção, o rendimento de matéria seca da parte aérea das plantas; a massa seca das amostras foi avaliada em estufa ventilada a $70{ }^{\circ} \mathrm{C}$ até atingir peso constante, expresso em tha- ${ }^{-1}$.

Adicionalmente, avaliou-se a eficiência do uso da água definida pela relação entre o rendimento de massa verde em $\mathrm{t} \mathrm{ha}^{-1}$ e a quantidade de água consumida pela cultura na parcela em $\mathrm{m}^{3} \mathrm{ha}^{-1}$, expressa em $\mathrm{t} \mathrm{m}^{-3}$ e depois transformada em $\mathrm{kg} \mathrm{m}^{-3}$; no entanto, para representar a quantidade de água consumida pela cultura em cada parcela e época de plantio, utilizou-se a média ponderada dos volumes por unidade de área evapotranspirado, obtidos em cada balanço hídrico, através da Eq. 5:

$$
\overline{\mathrm{V}}_{\mathrm{jk}}=\frac{\sum_{\mathrm{i}=1}^{\mathrm{n}} \mathrm{V}_{\mathrm{ijk}} \mathrm{N}_{\mathrm{i}}}{\sum_{\mathrm{i}=1}^{\mathrm{n}} \mathrm{N}_{\mathrm{i}}}
$$

em que:

$$
\begin{aligned}
\overline{\mathrm{V}}_{\mathrm{jk}}- & \text { volume médio por unidade de área evapotrans- } \\
& \text { pirado pela cultura, representativo do período } \\
& \text { de aplicação dos balanços hídricos no j-ésimo } \\
& \text { tratamento, na k-ésima repetição, } \mathrm{L} \mathrm{m}^{-2} \\
\mathrm{~V}_{\mathrm{ijk}}- & \text { volume por unidade de área evapotranspirado } \\
& \text { pela cultura no i-ésimo balanço hídrico do j- } \\
& \text { ésimo tratamento, na k-ésima repetição, } \mathrm{L} \mathrm{m}^{-2} \\
\mathrm{~N}_{\mathrm{i}}- & \text { número de dias correspondente ao fechamento } \\
& \text { do i-ésimo balanço hídrico } \\
\mathrm{n}- & \text { número de balanços hídricos aplicados no perí- } \\
& \text { odo experimental }
\end{aligned}
$$

\section{RESULTADOS E DISCUSSÃO}

As características vegetativas do coentro foram representadas pela altura de plantas na parcela útil APU, pelo rendimento de massa verde RMV e rendimento de massa seca RMS da parte aérea da planta, pelo número de plantas por parcela NPP e pela eficiência do uso da água EUA. Verifica-se, na Tabela 1, efeito significativo das épocas de observação T, em níveis de significância variando de 1 a $0,1 \%$ de probabilidade para todas as variáveis, exceto para RMV; ainda se tem, na mesma tabela efeito significativo da interação $\mathrm{H} \times \mathrm{L}$, em níveis de probabilidade na faixa de 1 a $0,1 \%$ para as variáveis estudadas, exceto NPP. Com relação ao efeito

\begin{tabular}{|c|c|c|c|c|c|c|}
\hline \multirow{2}{*}{$\begin{array}{l}\text { Fonte de } \\
\text { Variação }\end{array}$} & \multirow{2}{*}{ GL } & \multicolumn{5}{|c|}{ Quadrados Médios } \\
\hline & & APU & RMV & RMS & NPP & EUA \\
\hline $\mathrm{H}\left(\mathrm{dg} \mathrm{kg}^{-1}\right)$ & 4 & $28,85^{\star \star \star}$ & $25,54^{*}$ & $0,49^{\star *}$ & $944,4^{*}$ & $20,41^{\mathrm{NS}}$ \\
\hline $\mathrm{L}(\mathrm{mm})$ & 1 & $195,31^{* * *}$ & $323,56^{* * *}$ & $7,22^{* * *}$ & $2726,1^{* *}$ & $1,09^{\mathrm{NS}}$ \\
\hline $\mathrm{H} \times \mathrm{L}$ & 4 & $26,40^{\star \star \star}$ & $87,12^{\star \star \star}$ & $0,81^{\star * *}$ & $196,4^{\mathrm{NS}}$ & $71,45^{\star *}$ \\
\hline Resíduo (a) & 30 & 3,90 & 7,95 & 0,10 & 238,0 & 13,09 \\
\hline $\mathrm{T}$ & 1 & $30,01^{\star \star}$ & $0,18^{\mathrm{NS}}$ & $6,72^{\star \star \star}$ & $1757,8^{\star \star}$ & $1260,1^{\star \star \star}$ \\
\hline$L x T$ & 1 & $13,61^{*}$ & $5,54^{\mathrm{NS}}$ & $0,37^{\mathrm{NS}}$ & $5,51^{\mathrm{NS}}$ & $1,33^{\mathrm{NS}}$ \\
\hline $\mathrm{H} \times \mathrm{T}$ & 4 & $1,16^{\mathrm{NS}}$ & $7,76^{\mathrm{NS}}$ & $0,13^{\mathrm{NS}}$ & $228,8^{\text {NS }}$ & $13,41^{\mathrm{NS}}$ \\
\hline $\mathrm{L} \times \mathrm{H} \times \mathrm{T}$ & 4 & $5,39^{\mathrm{NS}}$ & $5,72^{\mathrm{NS}}$ & $0,19^{\mathrm{NS}}$ & $96,13^{\mathrm{NS}}$ & $6,21^{\mathrm{NS}}$ \\
\hline Resíduo (b) & 30 & 3,22 & 4,59 & 0,14 & 177,04 & 10,01 \\
\hline CV (a) \% & & 5,73 & 15,19 & 13,99 & 11,96 & 14,79 \\
\hline CV (b) \% & & 5,20 & 11,54 & 16,90 & 10,31 & 12,93 \\
\hline
\end{tabular}
isolado dos fatores $\mathrm{H}$ e L, observa-se que houve influência em níveis de significância variando de 5 a $0,1 \%$ para todas as características estudadas, menos para EUA; por sua vez, verificam-se coeficientes de variação menores que $17 \%$ indicando uma precisão adequada no experimento, tanto em nível de parcela quanto para os tratamentos em nível de subparcela.

Tabela 1. Resumo da ANOVA para altura de plantas, rendimento de massa verde e massa seca RMS, número de plantas, e a eficiência do uso da água, em função de doses de hidratassolo e a lâmina de irrigação nas épocas de observação

\begin{tabular}{|c|c|c|c|c|c|c|}
\hline \multirow{2}{*}{$\begin{array}{l}\text { Fonte de } \\
\text { Variação }\end{array}$} & \multirow{2}{*}{ GL } & \multicolumn{5}{|c|}{ Quadrados Médios } \\
\hline & & APU & RMV & RMS & NPP & EUA \\
\hline $\mathrm{H}\left(\mathrm{dg} \mathrm{kg}^{-1}\right)$ & 4 & $16,81^{*}$ & $8,39^{\mathrm{NS}}$ & $0,18^{\mathrm{NS}}$ & $483,1^{\star *}$ & $10,91^{\mathrm{NS}}$ \\
\hline $\mathrm{L}(\mathrm{mm})$ & 1 & $156,02^{\star \star \star}$ & $206,93^{\star \star \star}$ & $5,45^{\star \star \star}$ & $1243,2^{\star \star \star}$ & $0,0062^{\mathrm{NS}}$ \\
\hline $\mathrm{H} \times \mathrm{L}$ & 4 & $21,83^{\star *}$ & $53,85^{\star \star *}$ & $0,11^{\mathrm{NS}}$ & $122,9^{\text {NS }}$ & $29,20^{*}$ \\
\hline Resíduo & 30 & 5,12 & 6,70 & 0,093 & 89,97 & 8,70 \\
\hline CV \% & & 6,68 & 13,98 & 11,92 & 7,09 & 14,39 \\
\hline
\end{tabular}

${ }^{\star},{ }^{* \star} \mathrm{e}{ }^{\star \star \star}$ Significativos a $5 \% ; 1 \%$ e $0,1 \%$ de probabilidade pelo teste $\mathrm{F}$

Primeira época de plantio do coentro: Verifica-se, na Tabela 2, influência significativa da interação entre os fatores $\mathrm{H}$ x L para as variáveis RMS e NPP ocorrendo o inverso para o efeito isolado do fator hidratassolo $\mathrm{H}$ para a variável RMS; assim, realizou-se o desdobramento das interações $\mathrm{H} \times \mathrm{L}$ para as variáveis APU, RMV e EUA.

Tabela 2. Resumo da ANOVA para altura de plantas, rendimento de massa verde e massa seca, número de plantas por parcela, e a eficiência do uso da água, em função de doses de hidratassolo e a lâmina de irrigação na primeira época de observação

NS Não significativo até $5 \%$,

, ${ }^{* \star}$ e ${ }^{* * \star}$ Significativos a $5 \% ; 1 \%$ e $0,1 \%$ de probabilidade pelo teste $\mathrm{F}$

Constata-se, na Figura 2, a variação dos dados médios observados das características avaliadas APU (em cm), NPP, RMV (em t ha-1) e EUA (em $\mathrm{kg} \mathrm{m}^{-3}$ ), além dos dados médios estimados obtidos com as equações de regressão em função da variação de doses crescentes de hidratassolo (em $\left.\mathrm{dg} \mathrm{kg}^{-1}\right)$, e dos níveis da lâmina de irrigação na época de observação $\mathrm{T}_{1}$.

Tem-se, na Figura 2A, o modelo quadrático que se ajustou às médias para a altura de plantas em função da elevação de doses, fixando-se a lâmina $\mathrm{L}_{1}$, em que se estimou, pela derivada primeira, a dose de máxima eficiência $10,90 \mathrm{dg} \mathrm{kg}^{-1}$ 


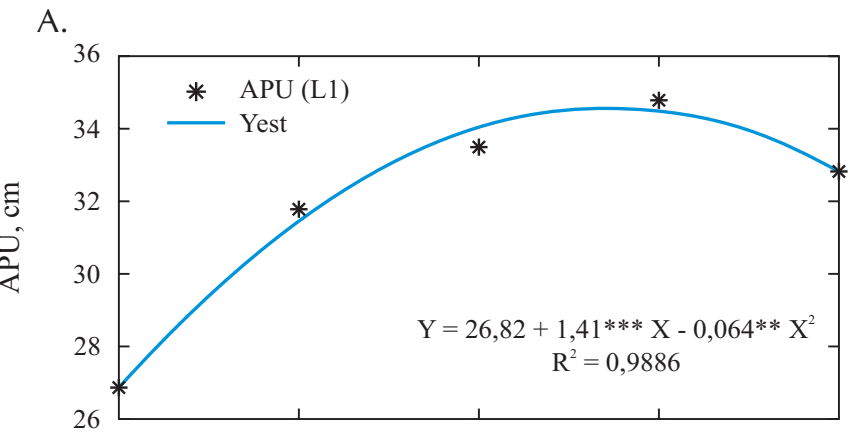

$$
\text { B. }
$$

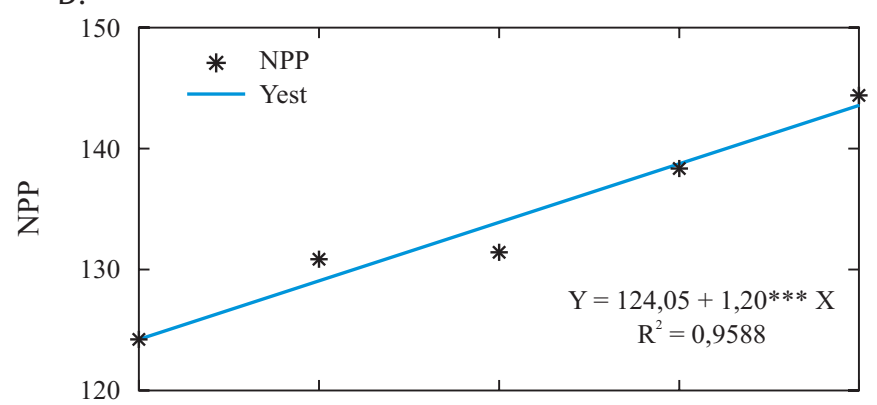

C.

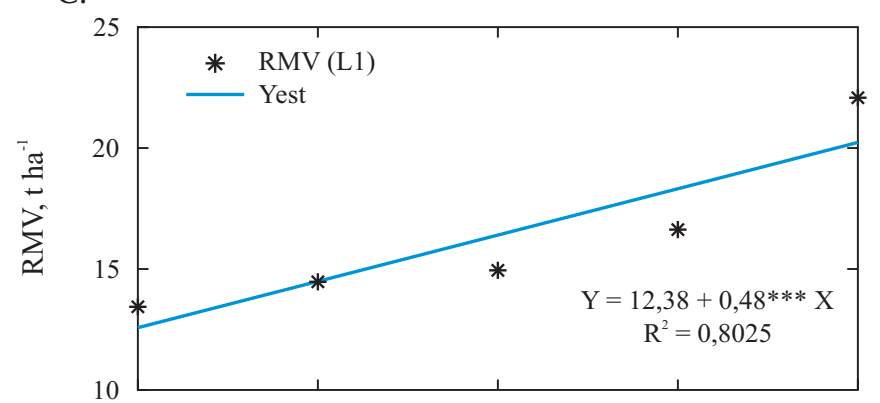

D.

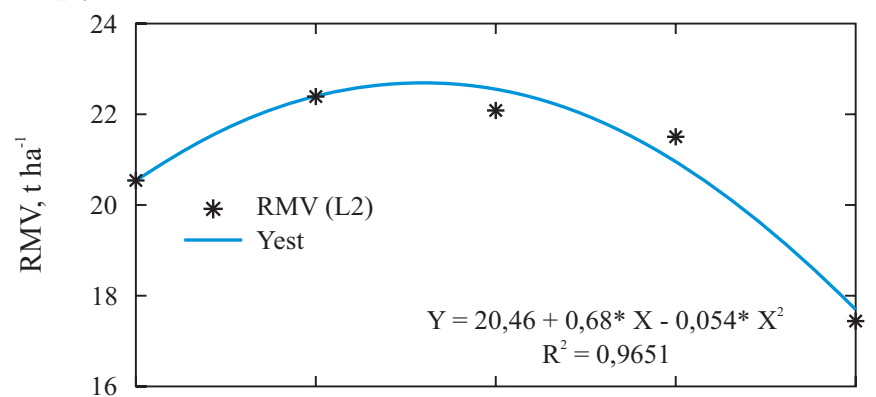

E.

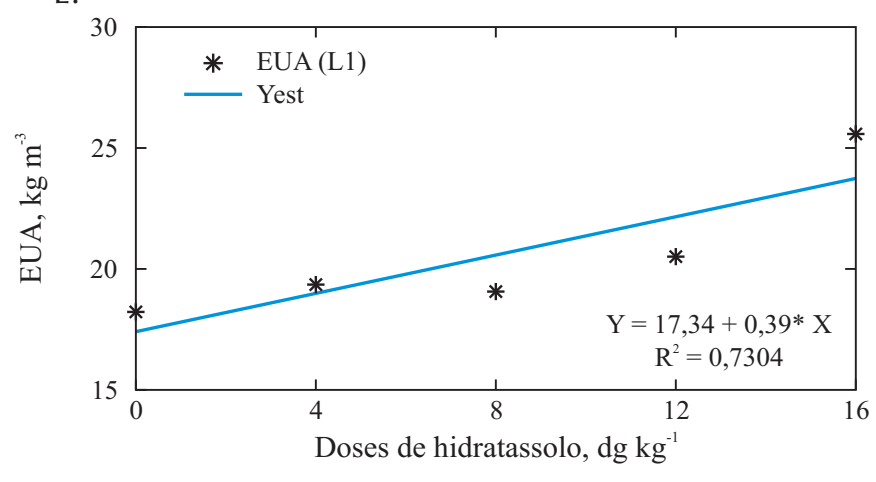

Figura 2. Altura de plantas na parcela útil - APU (A), número de plantas por parcela - NPP (B), rendimento de massa verde - RMV (C e D) e eficiência do uso da água - EUA (E), em função de doses de hidratassolo estimados nos níveis da lâmina de irrigação $\mathrm{L}_{1}\left(60 \%\right.$ ETo) e $\mathrm{L}_{2}(120 \% \mathrm{ETo})$ na primeira época de plantio $\left(\mathrm{T}_{1}\right)$ como aquela responsável pela altura máxima da planta de $34,51 \mathrm{~cm}$; com o uso do modelo se estimaram as alturas de plantas correspondentes ao tratamento testemunha e a dose máxima, com respectivos valores de 26,83 e $32,83 \mathrm{~cm}$. Com base nesses dados se observam incrementos de 28,62 e 22,36\% quando se relacionam as estimativas de APU (máxima) e APU $\left(\mathrm{H}_{4}\right)$ com a APU $\left(\mathrm{H}_{0}\right)$, respectivamente.

Para a variável RMV os respectivos modelos de regressão, conforme as Figura 2C e 2D, indicaram relação linear para lâmina $\mathrm{L}_{1}$ e quadrática para $\mathrm{L}_{2}$; no primeiro caso se verifica incremento de $62,21 \%$ quando se relacionam os valores de RMV obtidos com a dose $\left(\mathrm{H}_{4}\right)$ de 20,09 $\mathrm{tha}^{-1}$ e a dose $\left(\mathrm{H}_{0}\right)$ de $12,38 \mathrm{t}$ ha ${ }^{-1}$ porém, no segundo caso, pela derivada primeira da equação quadrática se estimou a dose de máxima eficiência de $6,37 \mathrm{dg} \mathrm{kg}^{-1}$ como responsável pelo valor máximo de RMV de 22,66 t ha-1; notam-se, também, incrementos de 28,38 e 15,92\% quando se comparam os respectivos valores estimados de RMV (máximo) com aqueles obtidos com a dose $\left(\mathrm{H}_{0}\right)$ de $20,46 \mathrm{tha}^{-1}$ e a dose $\left(\mathrm{H}_{4}\right)$ de $17,65 \mathrm{t} \mathrm{ha}^{-1}$.

Verifica-se, daí, que a maior dose de hidratassolo $\left(\mathrm{H}_{4}\right)$ proporcionou um valor de RMV, estimado pelo modelo, $13,73 \%$ menor que o valor de RMV estimado com a dose testemunha $\left(\mathrm{H}_{0}\right)$. Desta forma, é provável que a redução na produtividade da cultura observada com o tratamento: dose $\left(\mathrm{H}_{4}\right)$ e lâmina $\left(\mathrm{L}_{2}\right)$, esteja relacionada com o efeito do polímero hidroabsorvente nas propriedades físicas e hidráulicas do solo, tendo em vista que a elevação nas doses e a consequente expansão do polímero reduzem o espaço poroso do solo, diminuindo o movimento da solução e do ar no solo devido à redução do raio médio dos poros do solo arenoso, conforme constatação de Prevedello \& Balena (2000) e AlDarby (1996).

No caso do efeito isolado de doses de hidratassolo $(\mathrm{H})$ medido nos níveis de lâmina de irrigação (L), conforme a Figura 2B, os dados médios observados para a variável NPP se ajustaram linearmente com a elevação de doses. Com base no modelo, verifica-se que houve incremento de $15,52 \%$ comparando-se o valor estimado de NPP relacionado à dose $\mathrm{H}_{4}$ de 143 plantas por parcela com o valor estimado para a dose $\mathrm{H}_{0}$ de 124 plantas por parcela. Fixando-se a lâmina $\mathrm{L}_{1}$ para a variável EUA, a Figura $2 \mathrm{E}$ indica que os dados estimados com o modelo linear aumentaram com os níveis crescentes de doses; verificou-se, também, que o emprego da dose máxima $\left(\mathrm{H}_{4}\right)$ proporcionou incremento de $36,56 \%$ na eficiência do uso da água em relação à dose testemunha $\left(\mathrm{H}_{0}\right)$.

Segunda época de plantio do coentro: constata-se através da Tabela 3, que não ocorreu influência significativa da interação entre os fatores H x L para a variável NPP e, nem, tampouco do efeito isolado do fator hidratassolo $\mathrm{H}$ para as variáveis NPP e EUA; entretanto, nesta mesma tabela se verifica efeito significativo da interação para as variáveis APU, RMV, RMS e EUA.

Tem-se, na Figura 3, a variação dos dados médios das características avaliadas APU (em cm) e RMV (em tha-1) e os dados estimados obtidos com as respectivas equações de regressão, em função da variação de doses crescentes de hidratassolo (em $\mathrm{dg} \mathrm{kg}^{-1}$ ), medido nos níveis da lâmina de 
irrigação na época de observação $\mathrm{T}_{2}$. Com base na Figura 3A, tem-se que o modelo linear se ajustou às médias dos dados observados para a altura de plantas APU em função de doses de hidratassolo $(\mathrm{H})$, fixando-se a lâmina $\mathrm{L}_{1}$; nota-se, para a maior lâmina $L_{2}$, que na Figura $3 \mathrm{~B}$ a variação de doses influenciou significativamente a variação das alturas de plantas, conforme modelo quadrático.

Tabela 3. Resumo da ANOVA para altura de plantas, rendimento de massa verde e massa seca, número de plantas por parcela, e a eficiência do uso da água, em função de doses de hidratassolo e a lâmina de irrigação na segunda época de observação

\begin{tabular}{|c|c|c|c|c|c|c|}
\hline \multirow{2}{*}{$\begin{array}{l}\text { Fonte de } \\
\text { Variação }\end{array}$} & \multirow{2}{*}{ GL } & \multicolumn{5}{|c|}{ Quadrados Médios } \\
\hline & & APU & RMV & RMS & NPP & EUA \\
\hline $\mathrm{H}\left(\mathrm{dg} \mathrm{kg}^{-1}\right)$ & 4 & $13,21^{\star \star *}$ & $24,91^{\star \star}$ & $0,44^{\star}$ & $690,1^{\mathrm{NS}}$ & $22,90^{\text {NS }}$ \\
\hline $\mathrm{L}(\mathrm{mm})$ & 1 & $52,90^{\text {*** }}$ & $122,18^{\star \star \star}$ & $2,14^{\star * \star}$ & $1488,4^{*}$ & $2,42^{\mathrm{NS}}$ \\
\hline $\mathrm{H} \times \mathrm{L}$ & 4 & $9,96^{* *}$ & $38,99^{\star \star \star}$ & $0,89^{\star \star}$ & $169,5^{\mathrm{NS}}$ & $48,47^{*}$ \\
\hline Resíduo & 30 & 2,00 & 5,84 & 0,15 & 325,1 & 14,39 \\
\hline CV \% & & 4,03 & 12,99 & 19,88 & 14,50 & 13,34 \\
\hline
\end{tabular}

NS Não significativo até $5 \%$

${ }^{\star},{ }^{* \star} \mathrm{e}{ }^{\star \star \star}$ Significativos a $5 \% ; 1 \%$ e $0,1 \%$ de probabilidade pelo teste $\mathrm{F}$

Fixando-se a lâmina $\mathrm{L}_{1}$ verifica-se, para a variável APU, que a estimativa do maior valor, $36,80 \mathrm{~cm}$, correspondente à dose máxima $\mathrm{H}_{4}$, quando comparado com a estimativa do tratamento testemunha de $31,10 \mathrm{~cm}$, proporcionou incremento de $18,32 \%$. Quando se fixa a lâmina $\mathrm{L}_{2}$ verifica-se, pela derivada primeira do modelo, que a estimativa da dose de máxima eficiência $8,13 \mathrm{dg} \mathrm{kg}^{-1}$ proporcionou a estimativa da altura máxima da planta de $37 \mathrm{~cm}$; estimaram-se os respectivos valores de APU de 35,55 e 35,45 cm, correspondentes às doses $\mathrm{H}_{4}$ e $\mathrm{H}_{0}$; desta forma, é notório que o emprego da dose de máxima eficiência proporcionou incremento de $4,37 \%$ na altura de plantas quando se relaciona a APU estimada com a dose testemunha verificando-se, porém, decremento de 3,92\% quando se comparam os dados estimados de APU obtidos com a maior dose $\mathrm{H}_{4}$ e a dose de máxima eficiência.

Com relação ao efeito significativo da interação $\mathrm{H}$ x L na variação da produtividade da cultura RMV observa-se, nas Figuras 3C e 3D, que o comportamento das dosagens de hidratassolo dentro de cada lâmina de irrigação L foi similar ao ocorrido na altura de plantas, tendo em vista a ocorrência de relação funcional linear e quadrática quando se utilizam as respectivas lâminas $\mathrm{L}_{1}$ e $\mathrm{L}_{2}$ na variação da variável RMV; no primeiro caso, houve incremento de $35,47 \%$ na comparação do valor máximo estimado para RMV de 19,40 t ha $^{-1}$ com o valor mínimo estimado de RMV de 14,32 $\mathrm{t} \mathrm{ha}^{-1}$, obtidos com as doses $\mathrm{H}_{4} \mathrm{e} \mathrm{H}_{0}$, respectivamente.

Com base no comportamento quadrático na variação da variável RMV para a lâmina $\mathrm{L}_{2}$ estimou-se, pela derivada primeira, o valor de 7,75 $\mathrm{dg} \mathrm{kg}^{-1}$ para a dose de máxima eficiência como aquela responsável pelo valor máximo de RMV de $23,96 \mathrm{t} \mathrm{ha}^{-1}$; este valor máximo proporcionou incremento de $39,30 \%$ em relação ao valor estimado de RMV de 17,20 t ha $^{-1}$ obtido com a dose testemunha $\mathrm{H}_{0}$; observa-se também que o emprego da dose máxima $\mathrm{H}_{4}$ ocasionou decremento de $5,17 \%$ na estimativa do rendimento de massa verde, de $16,31 \mathrm{t} \mathrm{ha}^{-1}$ em relação à testemunha.

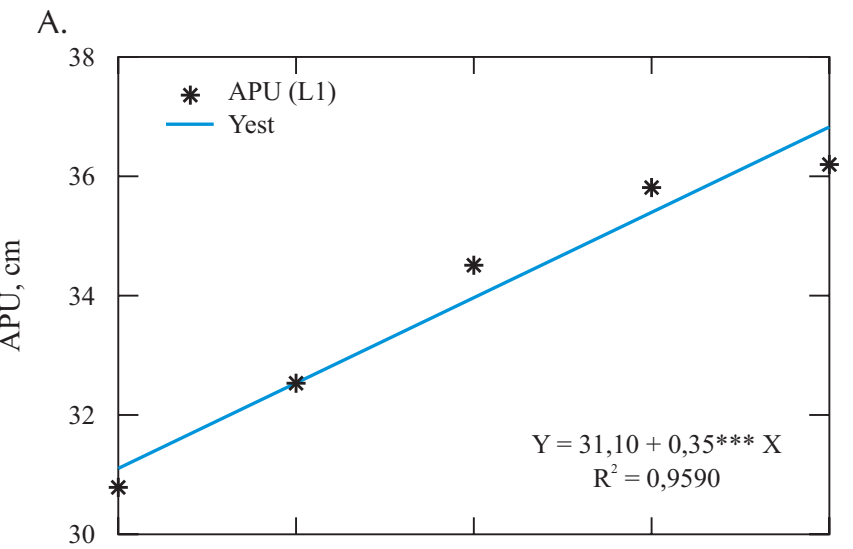

B.

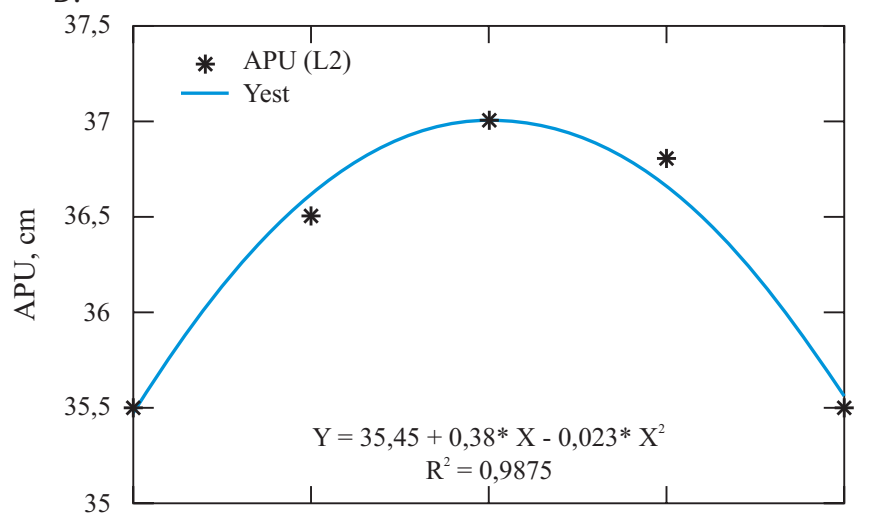

C.

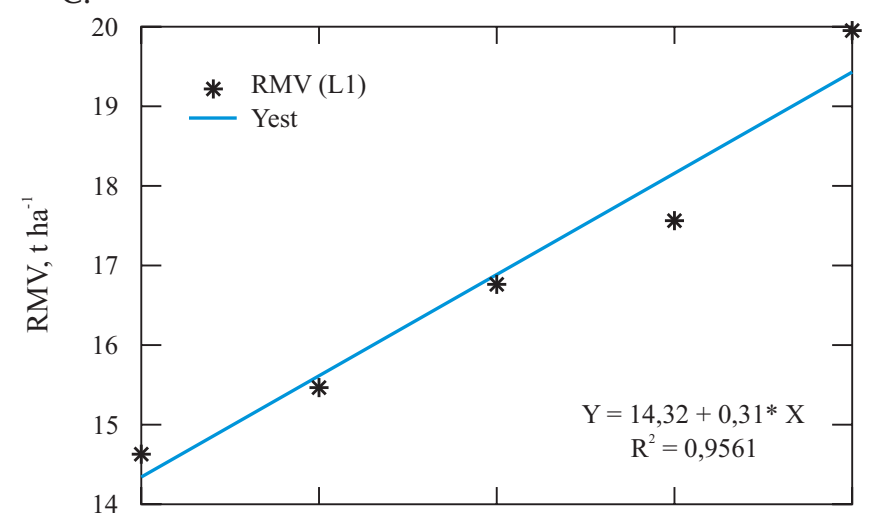

D.

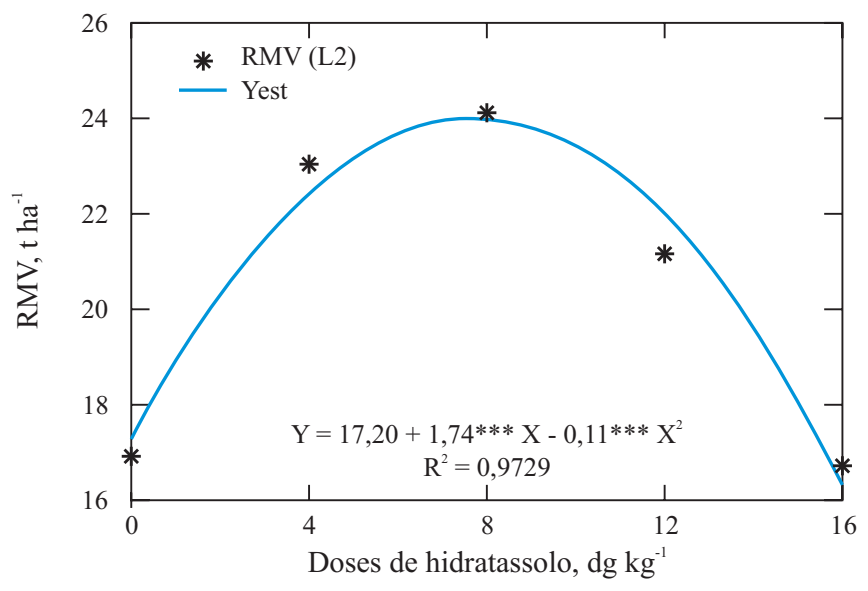

Figura 3. Altura de plantas na parcela útil - APU (A e B) e rendimento de massa verde - RMV (C e D), em função de doses de hidratassolo, respectivamente nos níveis das lâminas de irrigação $\mathrm{L}_{1}\left(60 \%\right.$ ETo) e $\mathrm{L}_{2}$ (120\% ETo), na segunda época de plantio $\left(\mathrm{T}_{2}\right)$ 
Na Figura 4, verifica-se a variação dos dados médios observados das características avaliadas EUA (em $\mathrm{kg} \mathrm{m}^{-3}$ ) e RMS (em t ha-1), e os dados estimados obtidos com as respectivas equações de regressão, em função da variação de doses crescentes de hidratassolo (em $\mathrm{dg} \mathrm{kg}^{-1}$ ), medido nos níveis da lâmina de irrigação na época de observação $T_{2}$ além, ainda, da ocorrência de relação funcional similar às análises da primeira época, ou seja, linear e quadrática relativa às respectivas lâminas de irrigação $\mathrm{L}_{1}$ e $\mathrm{L}_{2}$. Para a vari-

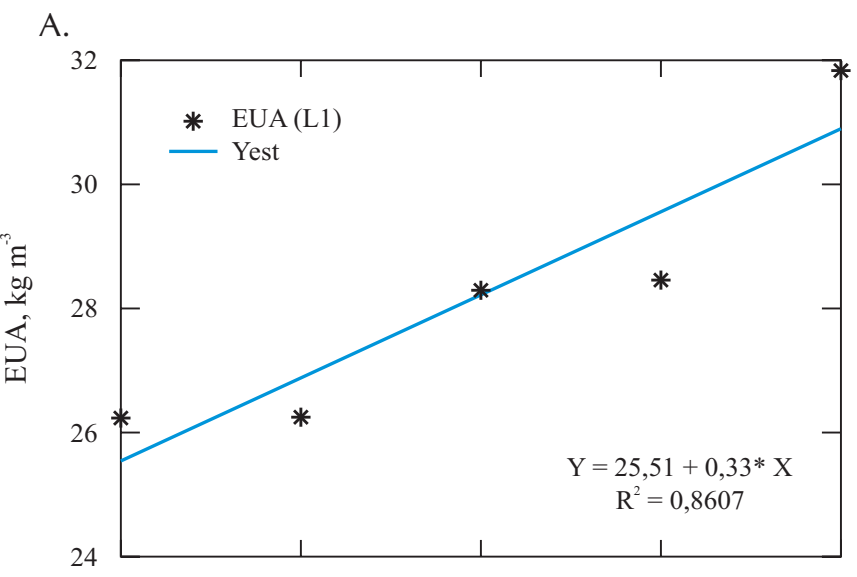

B.

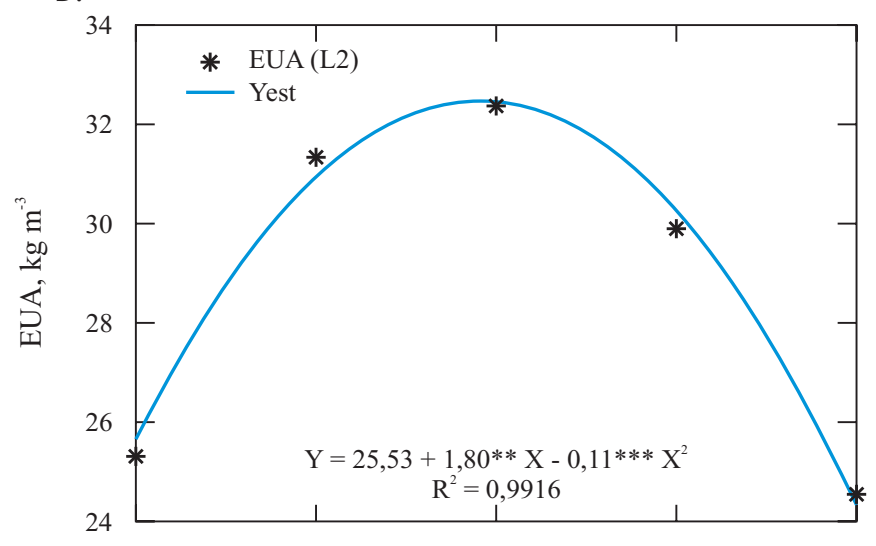

C.

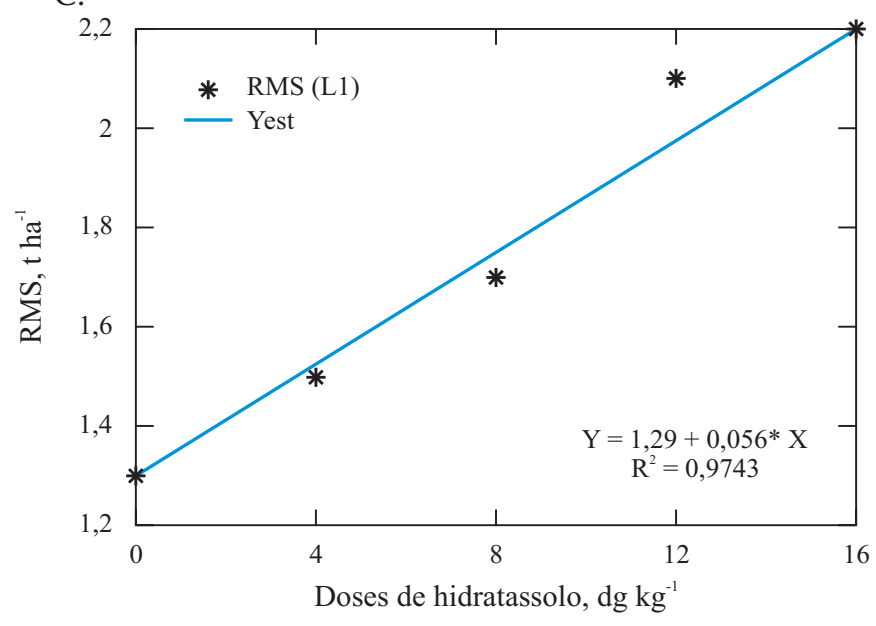

Figura 4. Eficiência do uso da água EUA para as lâminas de irrigação $L_{1}$ $\left(60 \%\right.$ ETo) (A) e $L_{2}(120 \%$ ETo) (B) e rendimento de massa seca - RMS (C) para a lâmina de irrigação $\mathrm{L}_{1}(60 \%$ ETo) em função de doses de hidratassolo $\mathrm{H}$, na segunda época de plantio $\left(\mathrm{T}_{2}\right)$ ável EUA observou-se indicação dos respectivos modelos, linear e quadrático quando se fixaram as respectivas lâminas de irrigação $\mathrm{L}_{1}$ e $\mathrm{L}_{2}$; assim, para a lâmina de irrigação $\mathrm{L}_{1}$ a eficiência do uso da água aumentou linearmente em função das doses de hidratassolo atingindo valor máximo estimado de $30,87 \mathrm{~kg} \mathrm{~m}^{-3}$ para a dose máxima $\mathrm{H}_{4}$ e incremento de $20,96 \%$ em relação à testemunha $\mathrm{H}_{0}$, e valor mínimo de EUA estimado em $25,52 \mathrm{~kg} \mathrm{~m}^{-3}$.

No entanto, no caso de se fixar a lâmina $\mathrm{L}_{2}$ para EUA e de posse do modelo estimou-se, pela derivada primeira, a dose de máxima eficiência em 7,68 $\mathrm{dg} \mathrm{kg}^{-1}$ como aquela responsável pelo valor máximo de EUA de $32,45 \mathrm{~kg} \mathrm{~m}^{-3} \mathrm{e}$ incremento de $27,10 \%$ em relação à testemunha, estimada em $25,53 \mathrm{~kg} \mathrm{~m}^{-3}$. O emprego da dose máxima $\mathrm{H}_{4}$ permitiu estimar o menor valor de EUA de $24,34 \mathrm{~kg} \mathrm{~m}^{-3}$ e decremento de $4,66 \%$ em relação à testemunha; desta forma, novamente se constata a ocorrência de queda da variável resposta em relação à testemunha, quando se utilizam a maior dose e a maior lâmina, fato que deve ser explicado pela influência do polímero na redução dos poros médios do solo devido à sua expansão em solo arenoso conforme constatação de Al-Darby (1996). Com base na possibilidade de redução dos poros médios do solo, supõe-se, ainda, que as parcelas que receberam a combinação do tratamento $\mathrm{H}$ x L, com seus níveis máximos, proporcionaram problemas de aeração no solo na zona radicular da planta.

Por sua vez e com relação à influência dos tratamentos na variação do rendimento de massa seca RMS, ainda se verifica comportamento similar ao que ocorreu para a variável RMV, ou seja, no caso de se fixar a lâmina $\mathrm{L}_{1}$ os resultados indicaram que a RMS aumentou linearmente com a elevação das doses; assim, o emprego da dose máxima $\mathrm{H}_{4}$ permitiu estimar o valor máximo de RMS em 2,19 tha ${ }^{-1}$ e incremento de $69,05 \%$ em relação à testemunha, estimado em $1,30 \mathrm{t} \mathrm{ha}^{-1}$.

\section{CONCLUSÕES}

1. Nas duas épocas de plantio do coentro a eficiência do uso da água, o rendimento de massa verde, o rendimento de massa seca e o número de plantas, aumentaram linearmente com a elevação das doses do polímero quando se fixa a menor lâmina, exceto para predição da altura de plantas na primeira época, avaliada por modelo quadrático.

2. Na aplicação da maior lâmina as estimativas das características vegetativas estudadas nas duas épocas foram maximizadas com doses ideais na faixa de 6 a $11 \mathrm{dg} \mathrm{kg}^{-1} \mathrm{e}$ o emprego da dose máxima $16 \mathrm{dg} \mathrm{kg}^{-1}$ proporcionou queda em relação à testemunha.

\section{AGRADECIMENTOS}

Os autores deste artigo expressam seus agradecimentos e fazem um tributo à memória do professor do Departamento de Tecnologia Rural da Universidade Federal Rural de Pernambuco, Ronaldo Freire de Moura, pelo reconhecimento 
do mérito e exemplo de dedicação, determinação e companheirismo.

\section{LITERATURA CITADA}

Aboukhaled, A.; Alfaro, A.; Smith, M. Lysimeters. Rome: FAO. 1982. 68p. Irrigation and Drainage, paper: 39.

Al-Darby, A. M. The hydraulic properties of a sandy soil treated with gel-forming soil conditioner. Soil Technology, v.9, p.15-28, 1996.

Azevedo, T. L. de; Bertonha, A.; Gonçalves, A. C. A. Uso de hidrogel na agricultura. Revista do Programa de Ciências Agro-Ambientais, v.1, n.1, p. 23-31, 2002.

Baasiri, M.; Ryan, J.; Muckeih, M.; Harih, S. N. Soil application of a hydrophilic conditioner in relation to moisture, irrigation frequency and crop growth. Soil Science, v.17, p.573-589, 1986.

Bernardi, A. C. de C.; Lucena Tavares, S. R. de; Angelune Schmitz, A. Produção de meloeiro utilizando um polímero hidrofílico em diferentes freqüências de irrigação em casa-de-vegetação. Irriga, v.10, n.1, p.82-85, 2005.

Danneels, P.; van Cotthem, W. The effect of a soil conditioning mixture on plant growth. Belgian Journal of Botany, v.127, n.1, p.17-25, 1994.

Filgueira, F. A. R. Manual de Olericultura: Cultura e comercialização de hortaliças, v.2, São Paulo: Agronômica Ceres, 1982. 357p.

Fonteno, W. C.; Bilderback, T. E. Impact of hydrogel on physical properties of coarse-struture horticultural substrates. Journal of the American Society for Horticulture Science, v.118, n.2, p.217-222, 1993.

Henderson, J. C.; Hensley, D. L. Efficacy of a hydrophilic gel as a transplant aid. Horticulture Science, v.21, n.4. p.991-992, 1986.
Johnson M. S. The effects of gel-forming polyacrylamides on moisture storage in sandy soils. Journal of Science Food Agricultural, v.35, p.1063-1066, 1984.

Oliveira, R. A. de; Rezende, L. S.; Martinez, M. A.; Miranda, G.V. Influência de um polímero hidroabsorvente sobre a retenção de água no solo. Revista Brasileira de Engenharia Agrícola e Ambiental, v.8, n.1, p.160-163, 2004.

Orzolek, M. D. Use of hydrophyllic polymers in horticulture. Horticulture Technology, v.3, n.1, p.41-44, 1993.

Pereira, R. S.; Muniz, M. F. B.; Nascimento, W. M. Aspectos relacionados à qualidade de sementes de coentro. Horticultura Brasileira, v.23, n.3, p.703-706, 2005.

Pill, W. G.; Jacono, C. C. Effects of hydrogel incorporation in peatlite on tomato growth and water relations. Communications in Soil Science and Plant Analysis, v.15, p.799-810, 1984.

Prevedello, C. L.; Balena, S. P. Efeito de polímeros hidrorretentores nas propriedades físico-hídricas de dois meios porosos. Revista Brasileira de Ciência do Solo, v.24, p. 251-258, 2000.

SAEG - Sistema para análises estatísticas, versão 9.0. Viçosa: Fundação Arthur Bernardes, 2005.

Sediyama, G. C. Necessidade de água para os cultivos. Brasília: ABEAS, 143p. módulo 4. 1987.

Taylor, K. C.; Halfacre, R. G. The effect of hydrophilic polymer on media water retention and nutrient availability to Ligustrum lucidum. Horticulture Science, v.21, p.1159-1161, 1986.

Tittonell, P. A.; De Grazia, J., Chiesa, A. Adición de polímeros superabsorbentes en el médio de crecimiento para la producción de plantines de pimiento. Horticultura Brasileira, v.20, n.4, p.641-645, 2002.

Wallace, A. Anionic polyacrylamide treatment of soil improves seedling emergence and growth. Horticulture Science, v.22, p.951, 1987.

Woodhouse, J.; Johnson, M. S. Effect of superabsorbent polymers on survival and growth of crop seedlings. Agricultural Water Management, v.20, p.63-70, 1991. 